\title{
Spatial and temporal variations of extreme precipitation and temperature events for the Southwest China in 1960-2009
}

\author{
Nianxiu Qin ${ }^{1,2}$, Junneng Wang ${ }^{1 *}$, Guishan Yang ${ }^{2}, X_{i}$ Chen $^{3}$, Haoyuan Liang ${ }^{1}$ and Jianbin Zhang
}

\begin{abstract}
Background: Extreme climate events leading to tremendous life and property losses, environmental degradation, have recently received increased attention. It is applied to a data set consisting of 116 weather station records (1960-2009) covering the Southwest China, and measured the spatial and temporal characteristics of precipitation and temperature extreme and their long-term trend have been analyzed, the possible reason for the recent 2009 SWC severe drought is briefly discussed too.
\end{abstract}

Results: The most remarkable result is, compared with the base year, significant decreasing trend has been measured for the precipitation amount and the rainy days while regardless the mean temperature, maximum temperature or minimum temperature is clear warming in 2009 over SWC, particularly in the 9-12 month, less precipitation combined with unreasonable high temperature may be the major contributor to the mega-drought crippling into SWC in 2009-2010. Although no significant trend has been indentified for annual precipitation, great sub-seasonality and regional difference has been detected over SWC. Statistical significant decreasing trend has been examined for rainy days over SWC and the downward prevail in the second half of a year, especially in the autumn month while the first half of a year is characterized by positive trend of maximum precipitation, rainy day intensity and annual precipitation. Maximum temperature and minimum temperature showed significant warming trend in every month, in particular the upward trend of the minimum temperature is stronger than that of the maximum temperature.

Conclusions: It is somewhat resulting easily in the increase of frequency of extreme events, that is, increase the frequency of flooding and drought in the Southwest China.

Keywords: Climatic change; Extreme climate events; Spatial and temporal variations; Statistical analyses; Southwest China

\section{Background}

The Fifth Assessment Report (AR5) of the United Nations Intergovernmental Panel on Climate Change (IPCC) pointed out that the global surface temperature increase reaches $0.85^{\circ} \mathrm{C}\left(0.65^{\circ} \mathrm{C}-1.06^{\circ} \mathrm{C}\right)$ (based on existing 3 independent data sets) from 1880 to 2012. Recent three ten years are the warmest than that of any other ten years since 1850.all over the world almost experienced heating process. Water cycle factors will be redistributed in time and space caused by global climate change, extreme

\footnotetext{
* Correspondence: Wjunneng@163.com

'Laboratory of Beibu Gulf Environment Change and Resources Use, Ministry of Education, Guangxi Teachers Education University, Nanning 530001, China Full list of author information is available at the end of the article
}

weather events will become more frequent, more intense, wider range induced by climate change with global warming characterized. (IPCC Fifth Assessment Report: Climate Change 2014). China's National Assessment Report on Climate Change also indicates that there is evidence for an increase in frequency of hydrological extreme events (China's National Climate Change 2007). Many extreme weather events have been reported in the recent all over the world, For example, As of May $25^{\text {th }}$, 25.1 percent of the Hawaiian Islands experienced extreme to exceptional drought conditions, as defined by the U.S. Drought Monitor (Source: Hawaii News Now); As of mid-June, 2010, northern and northeastern Thailand experienced its worst drought in nearly 
20 years (Source: Thailand Business News); Strong storms on June $14^{\text {th }}, 2010$ dumped up to $400 \mathrm{~mm}$ of rain in parts of the Var region in southeastern France. Meteo France reported that the rainfall event and subsequent flooding was the worst on record since 1827 (Source: BBC News), which have caused large losses of life, as well as a tremendous increase in economic losses, and a series of environment problem. These tremendous life and property losses raises the question as to whether extreme weather and climate events are truly increasing, whether this is only a perceived increase exacerbated by enhanced media coverage, or both (Karl and Easterling 1999; Easterling et al., 2000). Ungar (1999) examined the possibility of enhanced media attention biasing the public perception that extreme weather events are increasing. Results indicated that in the United States there appears to be an increase in media coverage, but in other parts of the world no increase was evident. These problems helped raise the alarm over the possibility that the recent increases were due to a shifting climate (Easterling et al. 2000; Brunetti et al. 2002).

Iwashima and Yamamoto (1993) used the data from scores of stations in Japan and the United States first to analyze the changes in heavy and extreme precipitation. A prominent indication of a change in extremes is the observed evidence of increases in heavy precipitation events over the mid-latitudes in the last 50 years, even in places where mean precipitation amounts are not increasing or even decreasing (IPCC Fourth Assessment Report: Climate Change 2007). Many scholars studied the characteristics of long-term changes of rainfall or heavy precipitation characteristics of long-term changes in Canada, Japan, Britain, Norway, South Africa, Brazil and the former Soviet Union, etc., they found the same phenomenon (Yamamoto and Sakurai, 1999; Groisman Pavel et al. 1999; Osborn, 2000). It has therefore been suggested that tests for climatic change should focus on changes in extreme events rather than on changes in climatic means (von Storch and Zwiers, 1988; Mason et al. 1999). In the recent years research on extreme climate events developed very rapidly and many studies have been performed all over the world (Karl et al., 1995; Suppiah and Hennessy 1998; Plummer et al., 1999; Brunetti et al., 2001; Pan, 2002; Zhai and Pan, 2003; Zhai et al., 2005; Goswami et al., 2006; Min and Qian, 2008, Chen et al., 2009). To study of extreme weather events has become the focus of climate change research.

Extreme weather and climatic events, particularly on the regional and local scales, are of paramount importance in assessing the socio-economic impacts of climate change. Southwest China (SWC) is potentially quite vulnerable to the economic damages caused by climate change. Although the mean precipitation amount with no significant increasing or decreasing trend has been observed during 1960-2007 for this area (Qin et al., 2010), the extreme events occur frequently in recent years. For example, in 2010, parts of southern China experienced heavy rains from May $31^{\text {st }}-$ June $2^{\text {nd }}$, More than $230 \mathrm{~mm}$ were recorded within a 12-hour period in Cenxi, Guangxi Automatic district (Source: Xinhua). Landslides and floods were responsible for at least 53 deaths and more than 200,000 people were evacuated from their homes (Source: AFP; Reuters). Nearly a week of torrential downpours from June 13th-18th led to more flooding in the South that killed at least 69 people and caused 240,000 to evacuate their homes. Sichuan provinces and the southern region of Guangxi were most severely affected by this round of storms, according to Xinhua news agency (Source: AFP); Most regions in eastern and middle-western Chongqing had suffered from heavy rainstorm in June, 2010, more than 10,000 houses toppled in the floods and 16,000 more damaged, and more than 1.5 million Chongqing residents have been affected by the rainstorm-triggered floods, and 123,000 have been relocated, direct economic losses amounted to 680 million yuan (\$100 million) (Wang and Zhan, 2010); And drought crippling SWC since autumn 2009 until May 2010 is the worst in a century. According to Xinhua, the nation's state media, the lack of rain and unseasonably high temperatures has also left 16 million people without easy access to drinking water; over 50 million people are affected; nearly a million hectares will not produce crops, while some rivers have dried up completely (Hance, 2010); Sichuan Province and Chongqing City suffered from severe high temperature and droughts in 2006 - the most serious drought since 1949 and leading to an economic loss of RMB10 billion (about 1.5 billion US Dollars).

Several studies have documented the spatial and temporal climate change trend in SWC. For example, Ding and Dai (1994) have reported a decreasing trend of annual mean temperature in SWC during 1951-1990. Chen and Zhu (1998) have confirmed the existence of this region, decreasing in temperature centered at Sichuan Basin during 1951-1995, Ma et al. (2006) have documented the climate change and variability of SWC. They have concluded that the Tibetan Plateau, the western Sichuan highland and Yunnan-Guizhou Plateau have been warmer and wetter during 1961-2000, but the northeastern and southwestern portions of Sichuan Basin showed a decreasing trend in temperature over the same period. and Qin et al. (2010) also gained the same results but the region with cooler temperature was shrinking due to the statistically significant increasing trend of temperature after 1990s, which is proved from the analysis of the temperature in this region has started to increase since late 1980s (Chen et al., 2004). Tang and Zhai (2005) pointed out that there was no statistically significant trend of annual temperature for SWC during 1951-2002. In addition, there were strong inter-annual and interdecadal variations of climate variables. Ban et al. 
(2006) have reported that the annual means of daily mean temperature, daily minimum temperature and daily maximum temperature have all increased since 1980s. However, the annual mean of daily maximum temperature has been decreasing since 1951. Qin et al. (2010) also pointed out that both annual and seasonal means of daily maximum and minimum temperatures show an increasing trend, but trend magnitude of minimum temperature was larger than that of maximum temperature, resulting in the decrease of diurnal temperature range for SWC during 1960-2007.

Dong and Duan (1998) studied the precipitation variability and trend in the SWC during 1951-1995 and concluded that annual, spring, summer and autumn precipitation showed an overall negative trend, and there were more negative than positive stations. A decreasing trend of annual precipitation during 1951-1999 in Sichuan Basin and Yunnan has also been identified by Liu et al. (2002), but there was not a statistically significant trend in the western and eastern portions of Sichuan and Guizhou Province. Zhang et al. (2007) analysed the rainfall trend and extreme events during 1961-2004 in Guizhou and reported significant increasing trends for annual mean rainfall amount in rainy season, maximum daily rainfall amount and times of annual occurrence of successive 3-, 5- and 7-day no-rainfall period. Spatially, the maximum daily rainfall amount decreased from the north to the south, and the increase in the occurrence of successive no-rainfall period decreased from the east to the west. Liu et al. $(2002,2007)$ have studied the spatial and temporal characteristics of precipitation and temperature in SWC during 1960-2000. They concluded that annual precipitation in the western portion of SWC has increased, but in the eastern part of SWC (except Chongqing) it has declined. There was a 14-year cycle of annual precipitation in the regions of the Western Sichuan Plateau, while the annual means of daily maximum and minimum temperatures had an obvious ascending tendency mixed with an 8-year cycle for the entire SWC. Xu et al. (2008) have analysed the climate patterns and trends in the Tibetan Plateau for the period from 1961 to 2001, and concluded that the temperature during the last several decades showed a long-term warming trend, especially in the areas around Dingri and Zogong stations, which formed two increasing centers. Only one of the stations they investigated exhibited a decreasing trend, and this was not statistically significant. Precipitation in the Tibetan Plateau has increased in most regions of the study area over the past several decades, especially in the eastern and central part, while the western Tibetan Region exhibited a decreasing trend over the same period. Annual precipitation showed slightly and statistically insignificant increasing trend, but statistically significant increasing trend has been detected in winter season while autumn witnessed a statistically significant decreasing trend (Qin et al., 2010).
However climate change studies for SWC over the past few decades have mostly focused on the changes in mean values (Ding and Dai, 1994; Liu et al. 2002; Chen et al. 2004; Ban et al. 2006; Liu et al. 2007; Cheng and Xie, 2008; Xu et al. 2008, Qin et al. 2010). The temporal and spatial variability of extreme rainfall and temperature events over SWC, its long term trend and its sub-seasonal variability are required to be discussed in detail. The objective of the present study is to examine these aspects of extreme rainfall and Maximum temperature events over SWC by taking daily rainfall and temperature data for 50 years from 1960 to 2009 .

\section{Climate extremes and data issues Study area}

SWC is located in the southeast of the "World Third Pole" Qinghai-Tibet Plateau, which falls within the provinces of Sichuan, Yunnan, Guizhou, Chongqing city and Guangxi with a total area of 1.36 million $\mathrm{km}^{2}$, between $21^{\circ}-35^{\circ} \mathrm{N}$ and $97^{\circ}-112^{\circ} \mathrm{E}$ (Figure 1 ). The altitude of this area ranges from 300 to $5000 \mathrm{~mm}$, the central high and the eastern and western low, the northern high and southern low, the formation is similar to "saddle" of the special different underlying surface. Plateau (the Yunnan-Guizhou Plateau), mountain (the Hengduan mountains), hill (eastern Sichuan hills) and Basin (the Sichuan basin) are four basic landscapes. The combined effect of the thermal effect and the dynamic action of the Tibetan Plateau forms the local weather systems, such as south branch trough, southwest vortex, Yunnan-Guizhou-stationary front, and thermal low pressure etc. in SWC (Xiong and Wang, 2008).

The climate is influenced by the topography. A typical subtropical monsoon climate prevail in this area, Dry and wet seasons are clearly defined, the rainy season usually begins in April, ends in October, annual precipitation varies between 980 and $1290 \mathrm{~mm}$ with an average of $1066 \mathrm{~mm}$, the highest of daily precipitation being 509.24 mm (Beihai, Guangxi, 1981-07-24), and the precipitation decreases from southeast to northwest. The average temperature is $15.61^{\circ} \mathrm{C}$, the highest being $43.5^{\circ} \mathrm{C}$ (Fuling, Chongqing, 2006-08-15).

\section{Data}

132 standard meteorological stations with daily precipitation and daily maximum temperatures, minimum temperatures in SWC were provided by the National Climate Center (NCC) of the China Meteorological Administration (CMA). Stations with data gaps were excluded, finally, 116 of which with continuous data series from 1960-2009 were used in this study. These stations, having high quality data, are maintained according to standard methods of the National Meteorological Administration of China, which applies data quality control before releasing these data. 


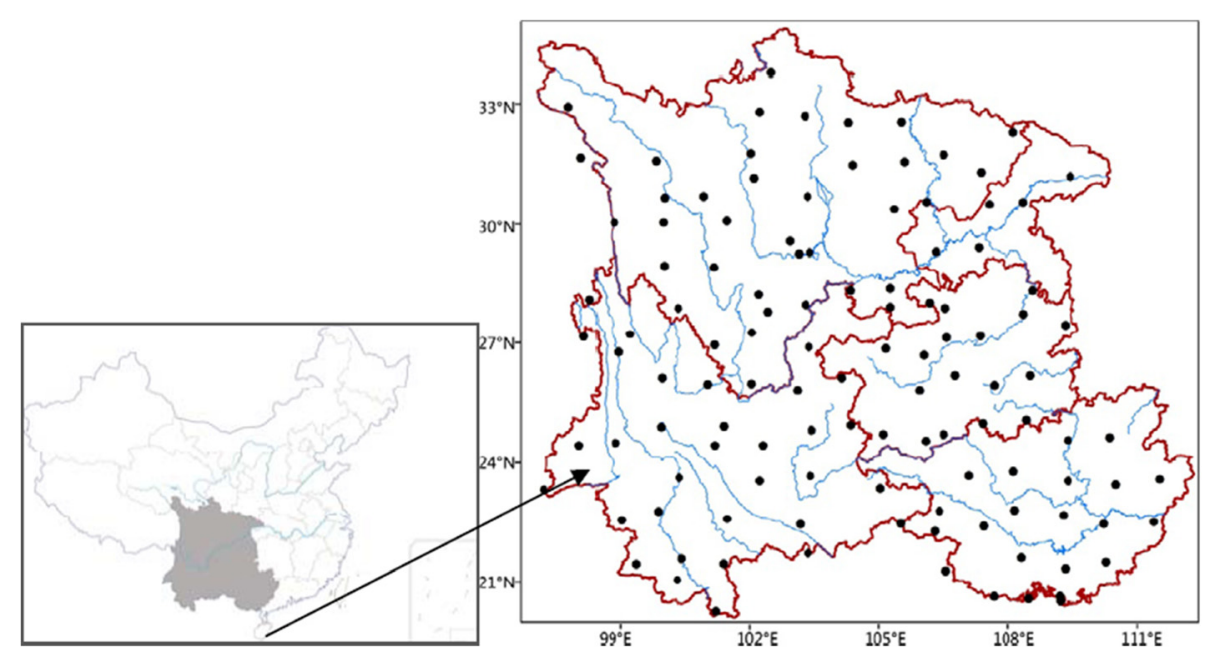

Figure 1 Location of the southwest China and climate stations used in this study.

\section{Methodology}

There are a number of ways extreme climate events can be defined. Based on the CMA classification, rainstorms are classified by minimum $50 \mathrm{~mm} \mathrm{~d}^{-1}$, however, if used the criteria to define rainstorm, larger area with nonrainstorm has been measured for SWC, and if accepting the criteria of the World Meteorological Organization, that is, extreme event means peak over threshold 90\%, it can boost the spatial comparability of change trend between dry area and wet area of heavy precipitation events (Su et al. 2006). Peak over threshold 90\%, 95\% and $99 \%$ are the daily precipitation above the $90 \%, 95 \%$ and 99\%-Percentile respectively. This study analyzed the extreme event of peak over threshold 90\%, 95\% and $99 \%$. A rainy day is considered at least $0.1 \mathrm{~mm} \mathrm{~d}^{-1}$ can be measured. Maximum precipitation or monthly maximum precipitation event, 3-day-maximum precipitation, 5-day-maximum precipitation and 7-day-maximum precipitation means annual or monthly maximum 3,5, 7 day total precipitation event respectively. Rain intensity is considered precipitation amount per rainy day (Gemmer, 2010).

Trend analysis has proved to be a useful tool for effective water resources planning, design, and management since trend detection of hydrological variables such as streamflow and precipitation provides a useful information on the possibility of change tendency of the variables in the future (Yue and Wang, 2004). The Mann-Kendall test $(\mathrm{MK})$ is one of the most popularly applied tests to detect trends in hydrologic time series. Annual and monthly trend of precipitation and temperature has been detected by the MK method at all 116 stations (1960-2009). The $90 \%$ and $95 \%$ confidence level was taken as threshold respectively to classify the significance of positive and negative trends for all indices. Detail description or reference list of the Mann-Kendall trend test is provided by Hirsch and Slack (1982) and Fu et al. (2004; 2009; 2010).

In order to estimate rainfall and temperature magnitude at unmeasured locations, a 2-deimensional, anisotropic inverse distance weighting (IDW) Spatial Interpolation method was applied to interpolate results for each station and to project the results 2-dimensional in the Geographical Information System (GIS) ArcGIS, which is one of the most commonly used techniques for interpolation of scatter points. The method consists of two parts. First, the optimum set of parameters for the IDW method is selected via cross-validation and the estimates are made using this optimal interpolator. Second, the uncertainty of each of the estimates is calculated via the jackknife procedure (Tomczak, 1998). Inverse distance weighted methods are based on the assumption that the interpolating surface should be influenced most by the nearby points and less by the more distant points. For the sake of the readability of the illustrations in the necessary size for this journal, maps showing the interpolated results using IDW method are shown.

\section{Results}

\section{Precipitation extremes}

\section{Spatial and Temporal Trends of annual precipitation}

\section{extremes}

Figure 2 shows the spatial distribution of annual maximum precipitation (the highest rainfall per day at one station per year) and their spatial pattern. Overall, annual maximum precipitation shows an increase from west to east and from Northwest to Southeast from less than $50 \mathrm{~mm}$ at the northwest of Sichuan province to more than $150 \mathrm{~mm}$ at the southernmost of Guangxi Zhuang Autonomous region, because of southwest monsoon or southeast monsoon climb along the windward 


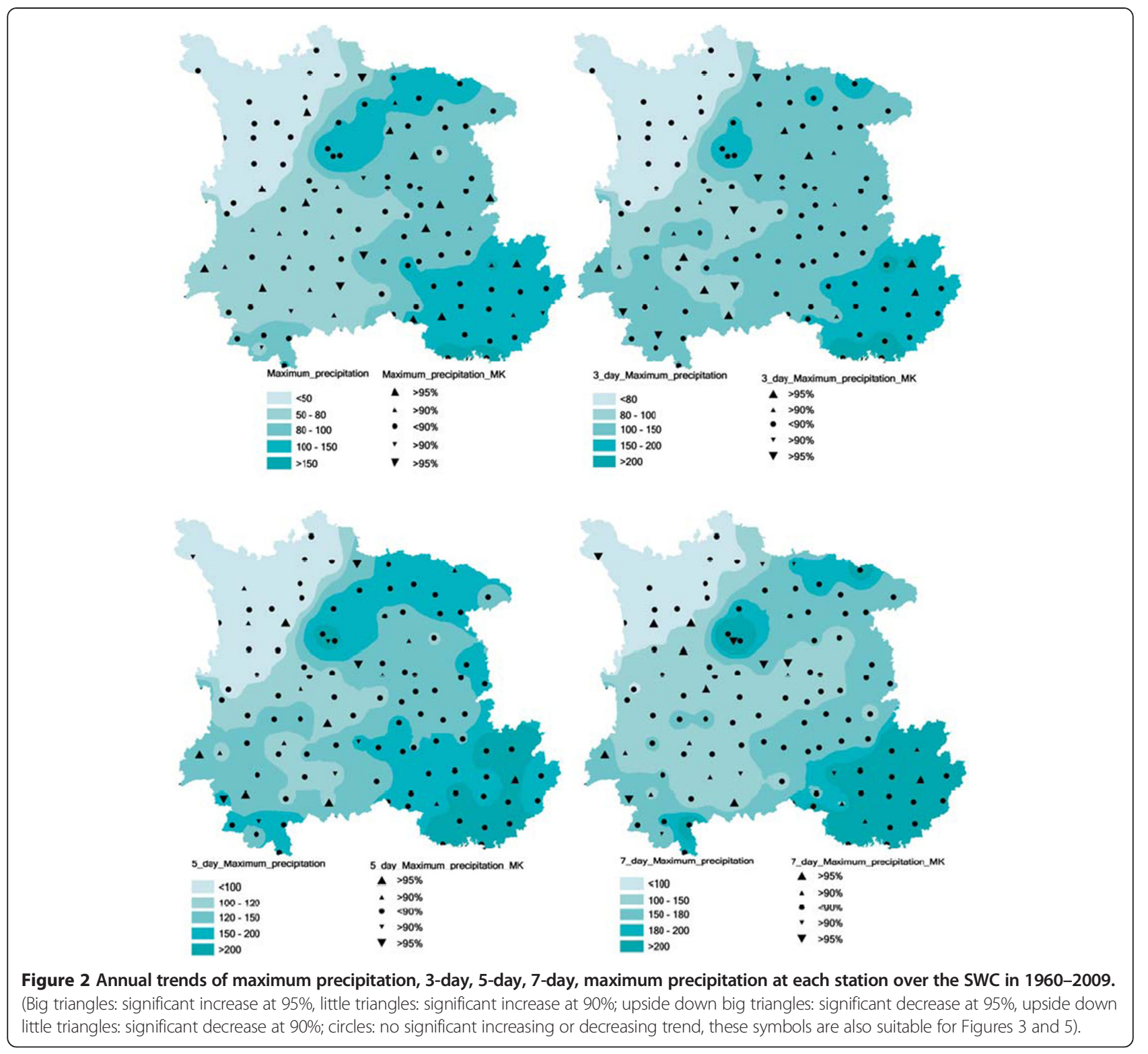

slope at the junction of Sichuan Basin and QinghaiTibet Plateau, resulting more than $100 \mathrm{~mm}$ rainstorm center has been examined here. Specially, annual maximum precipitation more than $100 \mathrm{~mm}$ is in Guangxi Zhuang Autonomous Region, between $80 \mathrm{~mm}$ and $100 \mathrm{~mm}$ in most part of Guizhou province and Chongqing city, all the whole Yunnan province is between $50 \mathrm{~mm}$ and $80 \mathrm{~mm}$ except the south, annual maximum precipitation of Sichuan province vary greatly, but an increasing from west to east range from less than $50 \mathrm{~mm}$ to more than $100 \mathrm{~mm}$, which indicate if using minimum $50 \mathrm{~mm} \mathrm{~d}^{-1}$ to define rainstorm, no rainstorm has been found here. Thus, extreme event of peak over threshold $90 \%$ is selected to define rainstorm in this study.
The MK was used to monitor annual maximum precipitation of the 116 stations in SWC. Only Thirty-three of 116 stations show significant trends above the $90 \%$ confidence level, of which seven are negative and twenty-six is positive, they are scattered in SWC province, which show slight increasing trend of annual maximum precipitation with $22.4 \%$ of the stations over SWC, no distinct decreasing signal can be found here.

The spatial extent of classes for the annual 3-daymaximum precipitation, the annual 5-day-maximum precipitation and the annual 7-day-maximum precipitation (long-term annual average) is similar to that of annual maximum precipitation (Figure 2). Annual 3-day(5-day and 7-day)-maximum precipitation below $100 \mathrm{~mm}$ are all 
mainly in northwest of SWC, that is, the western Sichuan Plateau, of course, below $100 \mathrm{~mm}$ of annual 3-daymaximum precipitation is stretch to the north and east of Yunnan province. More than $200 \mathrm{~mm}$ of annual 3-daymaximum precipitation mainly in south of Guangxi Autonomous region, more than $200 \mathrm{~mm}$ of annual 5-daymaximum precipitation from south extent to the whole south and some parts of north in Guangxi Autonomous region, more than $200 \mathrm{~mm}$ of annual 7-day-maximum precipitation extent even to the whole Guangxi Autonomous region, and also Ya'an, Yueshan, E'mei of Sichuan province. Results from the Mann-Kendall trend test indicated that 8(19), 8(17) and 10(12) of 116 stations only show negative (positive) trends of 3-day-maximum precipitation, 5-day-maximum precipitation and 7-day-maximum precipitation respectively on $90 \%$ confidence level. Therefore, the same to the annual maximum precipitation, a slight increasing trend has been indentified for 3-day (5-day and 7-day)-maximum precipitation, but no distinct decreasing trend of 3-day (5-day and 7-day)-maximum precipitation can be found here.

Extreme precipitation of the peak over threshold 90\%, 95\% and 99\% (Figure 3) all decrease from southeast to northwest less than $15 \mathrm{~mm}$ at the northwest of Sichuan plateau to more than $30 \mathrm{~mm}$ at most parts of Guangxi Zhuang Autonomous region at the peak over threshold $90 \%$, only east of Sichuan and south of Yunnan and Guizhou province, the peak over threshold $90 \%$ range from $25 \mathrm{~mm}$ to $30 \mathrm{~mm}$, most of SWC the peak over threshold $90 \%$ is between $20 \mathrm{~mm}$ and $25 \mathrm{~mm}$. For the peak over threshold $95 \%$, more than $50 \mathrm{~mm}$ is scattered in Southernmost of Guangxi Zhuang Autonomous region,

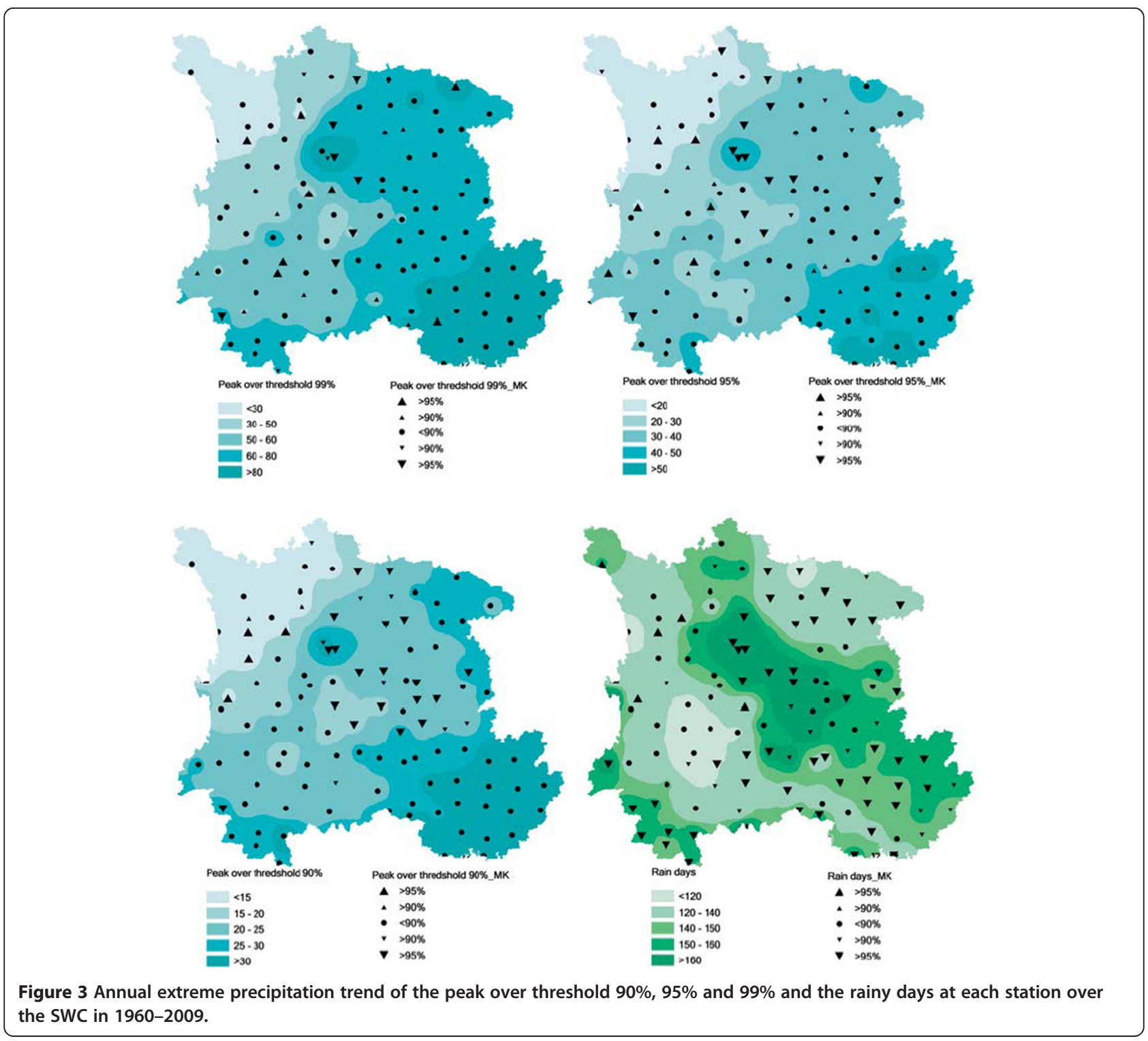


Ya'an and Yue shan of Sichuan province. the other parts of Guangxi Zhuang Autonomous region is more than $40 \mathrm{~mm}$, Guizhou, the east of Sichuan province, Chongqing city and the south of Yunnan province is between $30 \mathrm{~mm}$ to $40 \mathrm{~mm}$, less than $20 \mathrm{~mm}$ mainly in the northwest of Sichuan plateau. At the peak over threshold 99\%, the threshold is more than $80 \mathrm{~mm}$ in most of Guangxi Zhuang Autonomous Region, Guizhou, and the east of Sichuan province, Chongqing city and the south of Yunnan province is between $60 \mathrm{~mm}$ to $80 \mathrm{~mm}$, the threshold in most parts of Yunnan province range from $50 \mathrm{~mm}$ to $60 \mathrm{~mm}$. less than $50 \mathrm{~mm}$ concentrated on the northwest of Sichuan plateau.

Results of the MK for the peak over threshold 90\%, 95\% and 99\% shows that 27(8),19(15) and 11(20) stations appear negative (positive) trend above $90 \%$ confidence level respectively. It can be found that the Sichuan basin is characterized by negative trends for the three thresholds, particularly the peak over threshold $90 \%$ and $95 \%$, which is backed-up by Wang and Qian (2009) who detected extreme precipitation decreased in SWC and Pan (2002) who examined extreme precipitation decreased in Sichuan basin, South of the Yangtze river and Northeast China, but increased during the same time-series in west of Northwest China and southeast part of QinghaiTibetan Plateau. No significant trend can be measured in others.

Rainy days of most parts of SWC are more than 120 days (Figure 3), below 120 days is only in the small parts in middle of Yunnan province, the highest (more than 150 days even 160 days) is in north of Guangxi Autonomous Region, Guizhou province and some parts of south in Yunnan province. Results of the trend test for the number of annual rainy days show a strong decrease in rainy days with 70 stations (60\% of all stations) experienced a negative trend on $90 \%$ confidence level, even $47 \%$ showed a downward trend on $95 \%$ confidence level. These are widely located in every province, of which more than 87\% stations in Guangxi Autonomous Region showed negative trend on $90 \%$ confidence level, nearly all the stations rainy days showed negative trend in Guangxi. The negative trend of the rainy days for Sichuan province and Chongqing city mainly located in the Sichuan basin and east of Sichuan plain, in the west, two stations even show positive trend. The negative trend of the rainy days in Guizhou province mainly located in the west and east. For the Yunnan province, the decreasing trend of rainy days is scattered. Overall, rainy days showed statistically significant decreasing trend in SWC, distinct decline of rainy days have been reported in some areas of the world (Sivakumar, 1992; Brunetti et al. 2001, 2004; Pan, 2002; Seleshi and Zanke, 2004; Liu et al. 2006) while in others there appears to be a increase (Manton et al. 2001; Gao et al. 2002; Liebmann et al. 2004).

\section{Spatial and Temporal Trends of monthly precipitation extremes}

Applying the MK for indices on monthly basis shows more distinct results than the exercise on annual basis. Figure 4 displays the results of the trend test for 6 indices on monthly basis, indicating the number of stations that have experienced the trends.

In term of rainy days, overall, negative trend prevail for SWC. Except in January, February and March, number of stations showing positive trend are stronger than that of negative stations, particularly in January with 41 stations is by far the month with the highest number of positive trends of rainy days. Statistically significant negative trend has been detected in other months, the highest number of stations (79) with negative trends can be found in September which is the only month with no positive trends for the number of rainy days can be revealed, followed by November (69) and October (62).

The results for trends of monthly maximum precipitation have been calculated displayed the first half of a year (January- July) is characterized by positive trends, January with 60 stations is by far the month with the highest number of positive trends of monthly maximum precipitation, followed by February (36), and March (30); the negative trend in the second half of a year (AugustDecember) is slight stronger than that of positive trend, October with 19 stations is by far the month with the highest number of negative trends of monthly maximum precipitation.

In terms of the results for trends of month precipitation, exception is April and July month a nearly equal number of stations show positive and negative trends. Overall the change trend is similar to that of monthly maximum precipitation.

Positive trends of monthly rain day intensity prevail for SWC except August and October month, the negative trend is slight stronger than that of positive trend, the change trend of rain day intensity is the same to monthly maximum precipitation and monthly precipitation, January with 52 stations is still by far the month with the highest number of positive trends, followed by February (39), May (39) and July (31). And similar to rainy days, monthly maximum precipitation and monthly precipitation, increasing trend in the first half of a year is stronger than that of the second half of a year.

Generally, increasing trend in the first half of a year is stronger than that of the second half of a year for all precipitation indices, and January is the highest number of positive trend for these indices. Decreasing trend of these indices prevail in the second half of a year, mainly concentrated in the September, October and November autumn month, Summing up all the indicators, decreasing trend highlights on the October. It is noteworthy that little significant negative trends can be detected for 


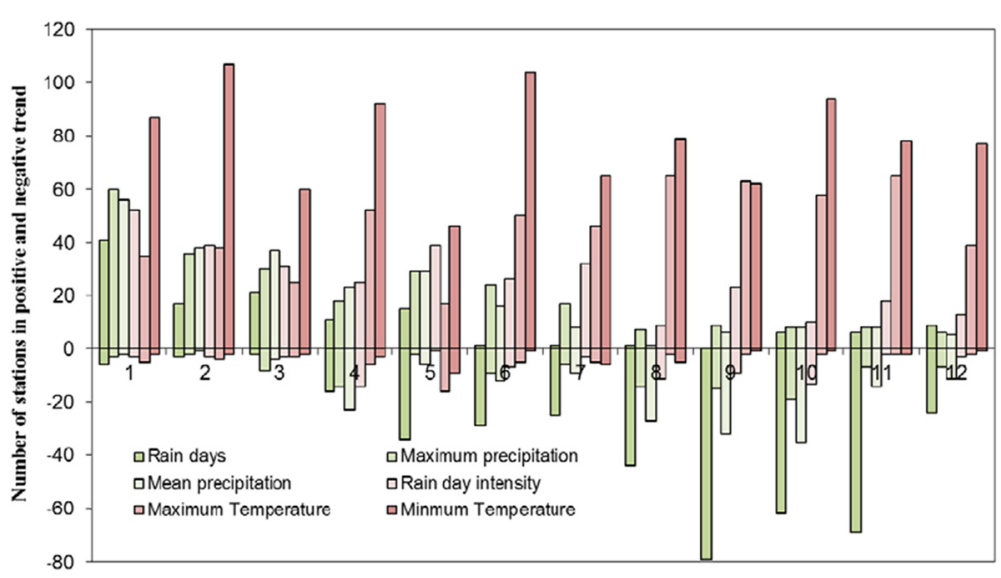

Figure 4 Observed monthly trends 1960-2009 at the 90 percent confidence level over SWC for six indices.

any of the indices between January and March. Taking all of the four precipitation indices into consideration, January (October) shows the most distinct positive (negative) trend of precipitation and its extremes, this is somewhat in line with the findings of Marco (2010). And the results indicated that despite little change in total precipitation, the uneven distribution of annual precipitation increased, which resulting in the increase of frequency of extreme events, that is, increase the frequency of flooding and drought.

\section{Temperature extremes}

Spatial and Temporal Trends of annual Temperature extremes Spatial and temporal trends of annual maximum temperature and minimum temperature extremes have been discussed in the next context. Figure 5 shows the spatial trends results. Annual maximum temperature below $30^{\circ} \mathrm{C}$ is scattered in the west of Sichuan plateau, more than $40^{\circ} \mathrm{C}$ is concentrated in the east of Sichuan Plain, between $30^{\circ} \mathrm{C}$ and $35^{\circ} \mathrm{C}$ concentrated in the west of Sichuan plateau and west and east of Yunnan province, between $35^{\circ} \mathrm{C}$ and $40^{\circ} \mathrm{C}$ concentrated in Guangxi, Guizhou, Middle of Sichuan and South and middle of Yunnan province. Results from the Mann-Kendall trend test reveal that significant positive trend of annual maximum temperature has been examined for SWC with 45 (9) stations showing positive (negative) trends on $90 \%$ confidence level. The positive trends can be observed in the west of Sichuan plateau and the YunnanGuizhou Plateau.

Annual minimum temperature for SWC is almost above $0^{\circ} \mathrm{C}$, below $0^{\circ} \mathrm{C}$ is only concentrated on the small part of northwest in Sichuan province, in fact, annual minimum temperature is above $10^{\circ} \mathrm{C}$ in most part of SWC, between $0^{\circ} \mathrm{C}$ and $10^{\circ} \mathrm{C}$ is located in the western of Sichuan plateau. Even above $15^{\circ} \mathrm{C}$ in Guangxi Autonomous Region. Compared with the annual maximum temperature,

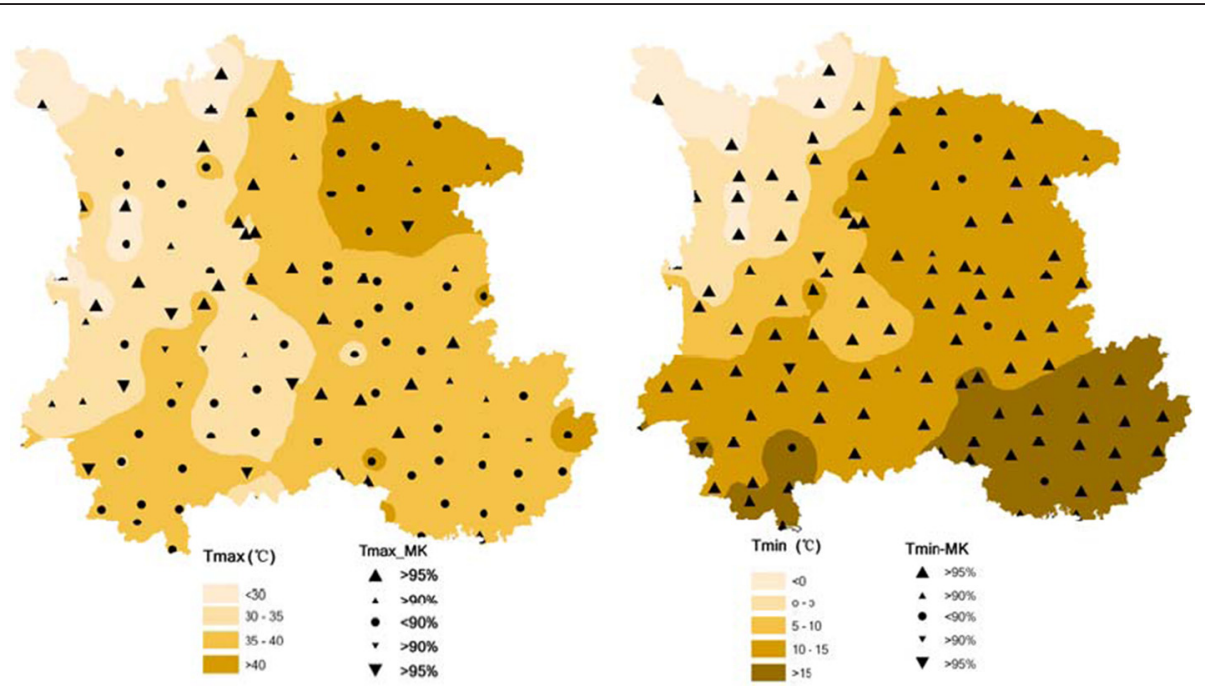

Figure 5 Annual trend of the maximum temperature and minimum temperature at each station over the SWC in 1960-2009. 
the trend test of annual minimum temperature indicated that statistically significant increasing trend has been indentified all over the SWC with 106 stations which is consist with the result of Pan (2002), only 3 station (Gengma, Yuanmou of Yunan province and Yuexi of Sichuan province) of 116 shows negative trend.

\section{Spatial and Temporal Trends of monthly temperature extremes}

Except May month a nearly equal number of stations of monthly maximum temperature show positive and negative trends, significant increasing trend of monthly maximum temperature has been observed in other month for SWC. In November (65) and August (65) the highest number of stations shows significant positive trends of monthly maximum temperature, in September, still 63 stations experienced positive trends. Overall, autumn month more than $50 \%$ stations of monthly maximum temperature shows increasing trend.

Monthly minimum temperature increasing trend is similar to that of monthly maximum temperature, but much stronger in strength than that of monthly maximum temperature in every month. More than 50\% number of station exhibited positive trend except May with only $40 \%$, February with $92 \%$ stations is by far the month with the highest number of positive trends of monthly maximum temperature, followed by June (90\%), then October (81\%). Increasing trend of monthly minimum temperature is very obvious.

\section{Precipitation and temperature in 2009}

Mega-drought hit Southwest China from autumn 2009 until May 2010 which is the worst in a century (Hance, 2010). The possible reason for the severe drought is briefly discussed in the next content. Due to the data of the first half of a year in 2010 has not yet been released by CMA. Here, we select $1960-1990$ as the base year to analysis the precipitation and temperature change in 2009 in detail from these indices of mean precipitation, rainy days, mean temperature, maximum temperature and minimum temperature.

\section{The change of precipitation}

Table 1 displayed the results of these indices for 2009 compared with the base year under annual and September-December month scale. Compared with the base year, The highest decreasing appear in Guizhou for annual mean precipitation in 2009 with nearly $20 \%$ decreasing, followed by Yunnan province (18\%), then Guangxi (13.49\%), overall, 13.76\% precipitation decreasing has been found for SWC in 2009. The change results of precipitation amount of September-December month in 2009 is similar to annual scale, but much stronger in strength than that of annual scale. The reduction is almost 30\%, and Guizhou and Yunnan province with $49.42 \%$ and $48.45 \%$ respectively is the highest. It can be seen that the precipitation in 2009 showed clearly decreasing compared with the base year; more pronounced reduction has been found during September-December month.

Compared with base year, the rainy days in 2009 reduced by approximately 20 days, the highest (36.25d) with decreasing can be found in Chongqing city, followed by Yunnan province (29.7d), and Guangxi (27.28d). For the change of rainy days of SeptemberDecember month, Yunnan province showed the highest decreasing days with $16.95 \mathrm{~d}$, compared with the base year, the decreasing is $42.22 \%$, followed by Chongqing city (14.61d and 31.57\%), and Guangxi (12.37d and 35.02\%).

Generally, compared with the base year, regardless of precipitation amount or rainy day, distinct reduction has been tested in 2009, especially in the month of September-December.

\section{The change of temperature}

Generally speaking, compared with the base year, regardless of mean temperature, maximum temperature or minimum temperature in 2009, temperatures increased significantly on annual and the month of September-December scale. The temperature warming close to $1^{\circ} \mathrm{C}$ on annual scale for all three indices, maximum temperature increasing is slight stronger in strength than that of mean temperature and minimum temperature, except in Guizhou province increasing is only $0.79^{\circ} \mathrm{C}$, the other four province, the increasing are above $1.15^{\circ} \mathrm{C}$, Yunnan province is the highest with $1.29^{\circ} \mathrm{C}$, followed by Chongqing city $\left(1.22^{\circ} \mathrm{C}\right)$, Sichuan $(1.18)$ and Guangxi (1.15), the warming is quite clear. The change of minimum temperature is almost similar to that of maximum temperature, compared with the base year, Chongqing city increasing is only $0.89^{\circ} \mathrm{C}$, the other four provinces, the increasing are above $1^{\circ} \mathrm{C}$, Sichuan province is the highest with $1.13^{\circ} \mathrm{C}$.

For the month of September-December scale, the same to annual scale, the maximum temperature increasing is slight stronger than that of mean temperature and minimum temperature, the increasing is also more than $1^{\circ} \mathrm{C}$ except Guangxi and Guizhou. Compared with the base year, Yunnan province and Sichuan province even reach $1.76^{\circ} \mathrm{C}, 1.44^{\circ} \mathrm{C}$ respectively. The warming of maximum temperature is very clear in 9-12 month. Compared with the base year, even the minimum temperature, more than $0.55^{\circ} \mathrm{Cwarming}$ has been detected. Thus, compared with the base year, clear warming has been found in 9-12 month 2009 for SWC.

\section{Interpretation: relation with large-scale circulation}

The spatial and temporal change trend of extreme precipitation and temperature has been investigated for 
Table 1 The change of temperature and precipitation compared with the base year (1960-1990)

\begin{tabular}{|c|c|c|c|c|c|c|}
\hline & Chongqing & Guangxi & Guizhou & Sichuan & Yunnan & SWC \\
\hline$P_{\text {change }}(\%)$ & -8.32 & -13.49 & -20.07 & -9.05 & -18.00 & -13.76 \\
\hline$P_{\text {change of 9-12 month }}(\%)$ & -30.42 & -27.80 & -49.42 & -27.42 & -48.40 & -35.76 \\
\hline $\mathrm{RD}$ change $(\%)$ & -36.25 & -27.28 & -22.46 & -17.57 & -29.70 & -23.86 \\
\hline $\mathrm{RD}_{\text {change of } 9-12 \text { month }}(\%)$ & -14.61 & -12.37 & -9.84 & -11.25 & -16.95 & -12.28 \\
\hline $\mathrm{T}_{\text {change of } \min }\left({ }^{\circ} \mathrm{C}\right)$ & 0.89 & 1.04 & 1.01 & 1.13 & 1.08 & 1.10 \\
\hline 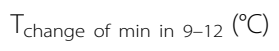 & 0.55 & 1.12 & 0.62 & 0.94 & 0.70 & 0.87 \\
\hline $\mathrm{T}_{\text {change }}\left({ }^{\circ} \mathrm{C}\right)$ & 0.89 & 1.07 & 0.84 & 1.02 & 1.09 & 1.04 \\
\hline $\mathrm{T}_{\text {change of } 9-12\left({ }^{\circ} \mathrm{C}\right)}$ & 0.69 & 0.96 & 0.55 & 1.09 & 1.12 & 0.96 \\
\hline $\mathrm{T}_{\text {change of } \max }\left({ }^{\circ} \mathrm{C}\right)$ & 1.22 & 1.15 & 0.79 & 1.18 & 1.29 & 0.97 \\
\hline $\mathrm{T}_{\text {change of max in } 9-12}\left({ }^{\circ} \mathrm{C}\right)$ & 1.10 & 0.72 & 0.53 & 1.44 & 1.76 & 1.02 \\
\hline
\end{tabular}

$\mathrm{T}_{\text {change }}=\mathrm{T}_{2009}-\mathrm{T}_{1960-1990 ;} \mathrm{P}_{\text {change }}=\left(\mathrm{P}_{2009}-\mathrm{P}_{1960-1990}\right)^{* 100 / \mathrm{P}_{1960-1990 ;} \mathrm{RD} \text { change }}$ (Rainy days $)_{(}\left(\mathrm{RD}_{2009-\mathrm{RD} 1960-1900}\right) * 100 / \mathrm{RD}_{1960-1990}$.

SWC in 2009 in detail. In general, rising temperatures lead to increased surface evaporation, coupling with less rainfall, will result in severe drought. The mega-drought of southwest China 2009-2010 may be due to these causes. But what cause less rainfall and unreasonable high temperature in 2009 over SWC?

Many scholars studied the change trend of temperature revealed that the significant warming has been detected, and the warming is more prominent in the winter and spring month (Du, 2001; Ren et al., 2005; Qin et al., 2010). Therefore, unreasonable extreme high temperature in 2009 over SWC may result from global warming.

The dynamic mechanism of extreme precipitation variability is complicated, combined with local climatic conditions, because the topography of SWC is rather complicated with the Yunnan-Guizhou Plateau, the western of Sichuan plateau, the Hengduan Mountains, eastern Sichuan hills and the Sichuan basin, the highest mountain chains of the Qinghai-Tibetan Plateau is located in the west of SWC, which resulting the microclimate is very prominent for SWC, combined with affect of the micro-climate, which lead to more complicated causes for precipitation over SWC. The significant impact of Qinghai-Tibetan Plateau on the distribution of water vapour flux and its seasonal variability has been measured, and there also has an important effect of the Sichuan Basin on water balance of payments of the surrounding area (Tao and Yi, 1999). The temporal and spatial evolution of Plateau-monsoon water vapour transport is the important scientific reference to recognize the cause of unusual droughts and floods in China and east Asia has been reported (Xu et al., 2002). It has long been recognized that the Tibetan Plateau, as the largest and highest Plateau in the world, affects the atmospheric circulation through land surface processes in addition to direct topographic influences (Zhao and Chen, 2001; Wu et al. 1998; Wu et al. 2004; Wu and Zhang, 1999; Liang et al. 2005; Zhu et al. 2007; Wang et al. 2008; Xu et al. 2008).

In addition, the precipitation variability of SWC may have a link with the El Nino-Southern Oscillation (ENSO) and the magnitude of East Asian Monsoon and Southwest Monsoon. The southern branch trough is the major weather system which affects the precipitation of SWC which is mainly from the Bay of Bengal (BOB), thus, also named the southern branch trough of the Bay of Bengal (SBTBB). The activity of SBTBB has distinct seasonality, mainly in from October to the next June, the most active period is in March to May, and the seasonal change and amount of SBTBB are closely related to the cold and warm air activities (Suo, 2008). It has been recognized that the onset of the BOB monsoon is directly linked to the thermal as well as mechanical forcing of the Tibetan Plateau (Wu and Zhang, 1998).

SST in the equatorial Pacific Ocean continues to increase. Since the beginning of May 2009, positive SST anomalies have been observed in all Niño regions (Sergei Rodionov. ENSO 2009-10: Chances of El Niño increased, 2009), the SST anomalies impact of this weakening of the southwest monsoon (Zhang et al. 2003). El Niño dissipated during May 2010 as positive surface temperature (SST) anomalies decreased rapidly across the equatorial Pacific Ocean and negative SST anomalies emerged across the eastern half of the Pacific (Climate prediction center/Ncep. La NIÑO/Southern Oscillation (ENSO) diagnostic discussion, 2010). The EAWM (East Asian Winter Monsoon) generally becomes weak when there is a positive SST anomaly in the tropical eastern Pacific (El Nino), and it becomes strong when there is a negative SST anomaly (La Nina) (Chen et al. 2000, Li et al. 2001; Yan et al. 2003; Huang et al. 2004). Zhou and $\mathrm{Wu}$ (2010) and $\mathrm{Mu}$ (2001) examined the respective impacts of the East Asian winter monsoon and ENSO on winter rainfall in China. They observed the influence of 
ENSO on winter rainfall is mainly in southern China whereas a weak EAWM, southerlies penetrate northward over eastern China winter rainfall, thus, which is not conducive to the formation of precipitation in SWC.

The date of summer monsoon onset over South China Sea (SCS) is consistent with the date of recurvature of wind, and link with the sea temperature anomaly and thermal regime over Tibetan Plateau (Chen et al., 1999, Feng and Li, 2009), in general, the monsoon onset over the eastern coast of the Bay of Bengal (BOB) in early May, end in October, It is followed by the onset of the East Asian monsoon over the South China Sea (SCS) by 20 May, then the onset of the South Asian monsoon over India by 10 June (Wu and Zhang, 1998), Thus, if the southwest monsoon end earlier or weaker in strength than normal year which leads to easily the emergence of the drought for SWC.

Wu and Qian (2003) studied the relation between the Tibetan winter snow and the Asian summer monsoon and rainfall and reported that light snow over the entire Tibet region, the south and Southeast Asian summer monsoon becomes weak, and there is less precipitation in SWC.

\section{Conclusions and discussion}

The spatial and temporal variability of the extreme precipitation and temperature events, its long term trend and its sub-seasonal variability over SWC is studied based on annual and monthly data for 1960-2009 in this investigation. The results indicated that annual maximum precipitation, 3-day (5-day and 7-day) maximum precipitation and extreme precipitation of the peak over threshold 90\%, 95\% and 99\% shows an increase from Northwest to Southeast and from west to east in SWC, which is consistent with the path of the rain belt moving. Because of southwest monsoon or southeast monsoon climb along the windward slope at the junction of Sichuan Basin and Qinghai-Tibet Plateau, which resulting another rainstorm center has been observed in this area. However, The MK showed that no clear trend of annual maximum precipitation can be found over SWC, only seven are negative and twenty-six is positive at above the $90 \%$ confidence level, and scattered in SWC province.

The spatial distribution of the annual 3-day-maximum precipitation, the annual 5-day-maximum precipitation and the annual 7-day-maximum precipitation is similar to that of annual maximum precipitation. Below $100 \mathrm{~mm}$ are all concentrated in the western Sichuan Plateau, more than $200 \mathrm{~mm}$ are mainly in Guangxi Autonomous Region, Ya'an of Sichuan province and south of Yunnan province. And the temporal change trend of the three indices is also similar to that of annual maximum precipitation, no significant trend has been found over SWC.
Most parts of SWC for rainy days are more than 120 days, more than 150 days even 160 days is in north of Guangxi Autonomous Region, Guizhou province and some parts of south in Yunnan province. Rainy day trend test indicated $70 \%$ stations experienced a negative trend, which widely located in every province, most part of SWC showed decreasing trend except some part of the western Sichuan Plateau and middle of Yunnan province.

Annual maximum temperature display increase from west to east, more than $40^{\circ} \mathrm{C}$ is concentrated in the east of Sichuan Plain, below $30^{\circ} \mathrm{C}$ is scattered in the west of Sichuan plateau. Trend test reveal that distinct positive trend of annual maximum temperature has been observed for SWC with 45 (9) stations showing positive (negative) trends on $90 \%$ confidence level. The positive trends can be found in the west of Sichuan plateau and the Yunnan-Guizhou Plateau.

Taking all of the above indices into consideration, we can conclude that rainy day and annual maximum temperature display significant trend on $90 \%$ confidence level, no distinct regions of other indices have experienced trends for annual indices.

The results for monthly scale showed that the negative trend of rainy day prevail for SWC, mainly concentrated in the September, October and November autumn month; while positive trend prevail for other indices of precipitation, and increasing trend in the first half of a year is stronger than that of the second half of a year. For the annual maximum temperature, positive trend are stronger clearly than that of negative trend in every month. Overall, January (October) shows the most distinct positive (negative) trend of precipitation and its extremes, this is somewhat in line with the findings of Marco (2010).

Compared with the base year, significant decreasing of the precipitation and rainy day in 2009 has been investigated, especially in the month of $9-12$, nearly $50 \%$ decreasing of precipitation has been measured for 9-12 month in Guizhou and Yunnan province while regardless of mean temperature, maximum temperature or minimum temperature in 2009 displayed increasing trend on annual and the month of 9-12 scale, compared with 1960-1990, the temperature increasing is closing to $1^{\circ} \mathrm{C}$ for SWC in 2009. Lack of rain and unseasonably high temperatures is the major contributor to the mega-drought crippling into SWC. Southwest drought is generally not caused by annual precipitation, and seasonal distribution or the uneven spatial and temporal distribution of precipitation (Yang et al., 2011). The analysis of drought in 2009 October to 2010 March in Southwest China, shows that the southern branch trough strength continued weak, groove of southwest air current water vapor transport is abate, the arrival of water vapor in the southwest region of China is correspondingly reduced, resulting in the severe 
drought in southwest area (Wang and $\mathrm{Li}, 2010$ ). And the analysis of the drought causes of the fall in 2009 to the spring in 2010, Huang et al. (2012) pointed out the Airflow anomaly over central and Southeast of Qinghai Tibet Plateau, which makes the water from the bay of Bengal cannot flow to the southwest of China, resulting in less precipitation and serious drought. At the same time, he also found the time is to should decay time of El Nino event, the anti cyclonic circulation anomaly in the lower troposphere over the tropical western Pacific, and then the anti cyclonic circulation anomaly from the tropical western Pacific through the South China Sea to the bay of Bengal lower troposphere over, it is the anti cyclonic circulation anomaly which induces the persistent severe drought in the southwest China (Huang et al., 2012).

In fact, there are many reasons for drought in the southwest, and the reason is also very complex. Different scholars give different disciplines of explanation. For example, the drought is a once-in-a-century climate phenomenon for the meteorological statistics, India ocean water vapors is separated by the Qinghai Tibet Plateau for the meteorological geography, the drought is caused by the earth exhaust and exhaust heat for the earth Meteorology, the drought is caused by the leakage of surface water of Karst landform for geology, the drought is blamed on the Known as the "pump" species speed species eucalyptus and rubber trees with Large area planting which absorb the excessive groundwater and surface water for biology (Yin and Li, 2013).

Although no distinct change in annual precipitation amount, significant change has been measured for monthly precipitation, overall, increasing trend prevail of maximum precipitation, rainy day intensity and annual precipitation in the first half of a year, which resulting easily in the increase of frequency of extreme events, that is, increase the frequency of flooding and drought.

\section{Competing interests}

The authors declare that they have no competing interests.

\section{Authors' contributions}

The work presented here was carried out in collaboration between all authors. QIN, LIANG and CHEN defined the research theme. QIN, WANG and LIANG designed methods and experiments, performed the statistical analysis, analyzed the data, interpreted the results and wrote the paper. ZHANG, CHEN AND YANG co-worked on conceived of the study, and participated in its design and coordination and helped to draft the manuscript, associated data collection and their interpretation. CHEN AND YANG co-designed experiments, discussed analyses, interpretation, and presentation. All authors have contributed to, read and approved the final manuscript.

\section{Acknowledgements}

This paper is financially supported by a National Basic Research Program ("973 Program", 2012CB417000), National Natural Science Foundation of China (Formation Mechanism and counter measures of extreme drought events in Southwest China under changing environments, Grant No. 41461007) and Guangxi science and Technology Department Program (Grant No. 2014DD29090). We would like to thank the National Climate Centre in Beijing, China, for providing valuable climate data.

\section{Author details}

'Laboratory of Beibu Gulf Environment Change and Resources Use, Ministry of Education, Guangxi Teachers Education University, Nanning 530001, China. ${ }^{2}$ State Key Laboratory of Lake Science and Environment, Nanjing Institute of Geography and Limnology, CAS, Nanjing 210008, China. ${ }^{3}$ State Key Laboratory of Hydrology-Water Resources and Hydraulic Engineering, Hohai University, Nanjing 210098, China.

Received: 13 July 2014 Accepted: 17 January 2015

Published online: 25 February 2015

\section{References}

Ban JM, Miao QL, Li X (2006) Analysis of characteristics of temperature variations in southwest China in recent 50 years. Resour Environ Yangtze Basin 15 (3):346-351 (in Chinese)

Brunetti M, Maugeri M, Nanni T (2001) Change in total precipitation, rainy days and extreme events in northeastern Italy. Int J Climatol 21(7):861-871

Brunetti M, Maurizio M, Teresa N, Antonio N (2002) Drought and extreme events in regional daily Italian precipitation series. Int J Climatol 22:543-558

Brunetti M, Maugeri M, Monti F, Nanni T (2004) Changes in daily precipitation frequency and distribution in Italy over the last 120 years. J Geophys Res 109: D05102, doi:10.1029/2003JD004296

Chen LX, Zhu WQ (1998) Study on climate change of China over the past 45 years. Acta Meteorologica Sinica 56(3):257-271 (in Chinese)

Chen LX, Liu HQ, Wang W, Wang YH, Yamazaki N (1999) Preliminary study on the characteristics and mechanism of summer monsoon onset over South China Sea and region adjacent to it. Acta Meteorologica Sinica 57(1):16-29

Chen W, Hans F, Graf HR (2000) The interannual variability of East Asian winter monsoon and its relation to the summer monsoon. Adv Atmos Sci 17(1):48-60

Chen LX, Zhou XJ, Li WL, Luo YF, Zhu WQ (2004) Characteristics of the climate change and its formation mechanism in china in last 80 years. Acta Meteorologica Sinica 62(5):634-645 (in Chinese)

Chen HS, Fan SD, Zhang XH (2009) Seasonal differences of variation characteristics of Extreme precipitation events over China in the Last 50 Years. Transact Atmos Sci 32(6):744-751

Cheng JG, Xie M (2008) The analysis of regional climate change features over Yunnan in recent 50 years. Progress in geography 27(5):19-26, in Chinese

China's National Climate Change Programme (2007), the National Development and Reform Commission (NDRC).

Ding YH, Dai XS (1994) Temperature variation in China during the last 100 years. Meteorol Monthly 20(12):19-26 (in Chinese)

Dong XQ, Duan X (1998) Climatic characteristics and variation tendency of precipitation in the southwest of China. Scientia Meteorological Sinica 18(3):239-247 (in Chinese)

Du J (2001) Change of temperature in Tibetan plateau from 1961 to 2000. Acta Geographica Sinica 56(6):682-690, in Chinese

Easterling DR, Evans JL, Groisman PY, Karl TR, Kunkel KE, Ambenje P (2000a) Observed variability and trends in extreme climate events: A brief review. Bull Am Meteorol Soc 81(3):417-425

Easterling DR, Meehl GA, Permesan C, Changnon SA, Karl TR, Mearns L (2000b) Climate extremes: observations, modeling, and impacts. Science 289:2068-2074

Feng J, Li JP (2009) Variation of the South China Sea summer monsoon and its association with the global atmosphere circulation and sea surface temperature. Chin J Atmos Sci (in Chinese) 33(3):568-580

IPCC Fifth Assessment Report: Climate Change, 2014

IPCC Fourth Assessment Report: Climate Change 2007

Fu GB, Chen SL, Liu CM, Shepard D (2004) Hydro-Climatic trends of the Yellow River Basin for the Last 50 Years. Clim Change 65(1-2):149-178

Fu GB, Charles SP, Yu JJ, Liu CM (2009) Decadal climatic variability, trends and future scenarios for the North China Plain. J Climate 22:2111-2123

Fu GB, Barber MB, Chen SL (2010) Hydro-climatic variability and trends in Washington State for the last 50 years. Hydrological processes. (in press). doi:10.1002/hyp.7527

Gao XJ, Zhao ZC, Filippo giorgi (2002) Changes of extreme events in regional climate simulations over East Asia. Advances in atmospheric sciences 19(5):927-942

Gemmer M, Thomas F, Tong J, Buda S, Lü Liu L (2011) Trends in Precipitation Extremes in the Zhujiang River Basin, South China. Journal of climate 24:750-761

Goswami BN, Venugopal V, Sengupta D, Madhusoodanan MS, Xavier PK (2006) Increasing trend of extreme rain events over India in a warming environment. Science 314:1442-1445 
Groisman Pavel Ya, Karl Thomas R, Easterling David R, Knight Richard W, Jamason Paul F, Hennessy Kevin J, Suppiah Ramasamy, Page Cher M, Wibig Joanna, Fortuniak Krzysztof, Razuvaev Vyacheslav N, Douglas Arthur, Forland Eirik, Zhai PanMao (1999) Changes in the Probability of Heavy Precipitation: Important Indicators of Climatic Change, Climatic Change. 42:243-283

Hance M (2010) Drought crippling southwest China, millions without drinking water [Available online at http://www.enn.com/climate/article/41148 china drought.html].

Hirsch RM, Slack JR (1982) Techniques of trend analysis for monthly water quality data. Water Resour Res 18(1):107-121, http://lwf.ncdc.noaa.gov/sotc/? report=hazards\&year $=2010 \&$ month $=5$

Huang RH, Chen W, Yang BL, Zhang RH (2004) Recent advances in studies of the interaction between the East Asian winter and summer monsoons and ENSO cycle. Adv Atmos Sci 21(3):407-424

Huang R, Liu Y, Wang L, Wang L (2012) Analysis of the causes of severe drought occurring in Southwest China from the fall of 2009 to the Spring of 2010. Chin J Atmos Sci 36(3):443-457, in Chinese

Iwashima T, Yamamoto R (1993) A statistical analysis of the extreme events: Long-term trend of heavy daily precipitation. J Meteorol Soc Jpn 71:637-640

Karl TR, Easterling DR (1999) Climate extremes: Selected review and future research directions. Clim Change 42:309-325

Karl TR, Knight Richard W, Neil P (1995) Trends in high-frequency climate variability in the twentieth century. Nature 377:217-220

Li CY, Sun SQ, Mu MQ (2001) Origin of the TBO-interaction between anomalous East-Asian winter monsoon and ENSO cycle. Adv Atmos Sci 18(4):554-566

Liang XY, Liu YM, Wu GX (2005) The Impact of Qinghai-Xizang Plateau uplift on Asian general circulation in spring and summer. Plateau Meteorol 24(6):837-845

Liebmann B, Vera Carolina S, Carvalho LMV, Camilloni Ines Hoerling A, Martin P, Allured D, Barros Vicente R, Baez Julian Bidegain M (2004) An Observed Trend in Central South American Precipitation. J Climate 17:4357-4367

Liu Y, Wang QQ, Cheng ZQ (2002) Regional features of summer rainfall anomaly over southwest China. J Nanjing Inst Meteorol 25(1):105-110 (in Chinese)

Liu XH, Ji ZJ, Wu HB, Yu X (2006) Distribution characteristics and interdeeadalfifelence of daily temperature and precipitation extremes in China for latest 40 years. J Tropical Meteorol 22(6):618-624, in Chinese

Liu XR, Li GP, Fan GZ, Chen BY, Li HQ (2007) Spatial and Temporal Characteristics of Precipitation Resource in Southwest China during 1960-2000. J Nat Resour 22(5):783-792 (in Chinese)

Ma ZF, Peng J, Gao WL, Tian H (2006) Climate variation of Southwest China in recent 40 years. Plateau Meteorol 25(4):633-642 (in Chinese)

Manton MJ, Della-Marta PM, Haylock MR, Hennessy KJ, Nicholls N, Chambers LE, Collins DA, Daw G, Finet A, Gunawan D, Inape K, Isobe H, Kestin TS, Lefale P, Leyu CH, Lwin T, Maitrepierre L, Ouprasitwong N, Page CM, Pahalad J, Plummer N, Salinger MJ, Suppiah R, Tran VL, Trewin B, Tibig I, Yee D (2001) Trends in extreme daily rainfall and temperature in Southeast Asia and the South Pacific: 1961-1998. Int J Climatol 21(3):269-284

Mason SJ, Waylen PR, Gillian M, Balakanapathy R, Michael Harrison J (1999) Changes in extreme rainfall events in South Africa. Clim Change 41:249-257

Min S, Qian Y (2008) Regionality and persistence of extreme precipitation even in China. Adv Water Sci 19(6):763-771, in Chinese

Mu MQ (2001) A further research on the cycle relationship between anomalous east-Asia winter monsoon and ENSO. Climatic Environ Res 6(3):273-285, in Chinese

Osborn TJ, Hnhne M, Jones PD, Basnett TA (2000) Observed trends in the daily intensity of United Kingdom precipitation. Int J Climatol 20(4):347-364

Pan XH (2002) The Spatial and Temporal Characteristics of Change of Temperature and Precipitation Extremes over China during the Second Half of the 20th Century. Master thesis, Chinese Academy of Meteorological Sciences

Plummer N, Salinger M, James NN, Ramasamy S, Hennessy Kevin J, Leighton Robert M, Blair T, Page Cher M, Lough JM (1999) Changes in Climate Extremes Over the Australian Region and New Zealand During the Twentieth Century. Clim Change 42(1):183-202

Qin N, Chen Xi F, Guobin ZJ, Xianwu X (2010) Precipitation and temperature trends for the Southwest China: 1960-2007. Hydrolog Process. doi:10.1002/hyp.7792

Ren GY, Xu MZ, Zy C, Guo J, Qx L, Liu X, Wang Y (2005) Changes of Surface Air Temperature in China during 1951-2004. Clim Environ Res 10(4):717-727 (in Chinese)

Rodionov S (2009) Available online at (http://www.climatelogic.com)

Seleshi Y, Zanke U (2004) Recent changes in rainfall and rainy days in Ethiopia. Int J Climatol 24:973-983
Sivakumar MVK (1992) Climate change and implications for agriculture in Niger. Clim Change 20(4):297-312

Su BD, Jiang T, Ren GY, Chen ZH (2006) Observed trends of precipitation extremes in the Yangtze River basin during 1960 to 2004. Adv Clim Change Res 2(1):9-14

Suo MQ. 2008. Formation, propagation and evolution characteristics of wintertime southern branch trough in the subtropical westerlies and its impacts on the weather and climate in China. Master thesis, Chinese Academy of Meteorological Sciences. (in Chinese).

Suppiah R, Hennessy KJ (1998) Trends in total rainfall, heavy rain events and number of dry days in Australia, 1910-1990. Int J Climatol 18(10):1141-1164

Tang HY, Zhai PM (2005) Comparison of variations of surface air temperatures in eastern and western China during 1951-2002. Chin J Geophysics 48(3):526-534 (in Chinese)

Tao ST, Yi L (1999) The role of Qinghai-Tibet Plateau in hydrological cycle of the Asian monsoon region. See Tao SY Chen LS, XU XD. The second theory of Tibetan Plateau Research of atmospheric scientific experiments. Meteorological Press, Beijing, pp 204-214

Tomczak M (1998) Spatial interpolation and its uncertainty using automated anisotropic Inverse distance weighting (IDW)-cross-validation/Jackknife approach. J Geogr Inform Decis Anal 2(2):18-30

Ungar S (1999) Is strange weather in the air? A study of U.S. national network news coverage of extreme weather events. Clim Change 41:133-150

Von Storch H, Zwiers FW (1988) Recurrence Analysis of Climate Sensitivity Experiments'. J Climate 1:157-171

Wang B, Li Y (2010) Relationship Analysis between South Branch Trough and Severe Drought of Southwest China during Autumn and Winter 2009/2010. Plateau Mt Meteorol Res 30(4):28-37, in Chinese

Wang ZF, Qian YF (2009) Frequency and intensity of extreme precipitation events in China. Adv Water Sci 20(1):1-9, in Chinese

Wang HY, Zhan LS (2010) Rainstorm kills 10 in SW China's Chongqing. [Available online at http://www.chinadaily.com.cn/china/2009-08/06/content_8534109.htm].

Wang TM, Wu GX, Wan RJ (2008) Influence of the Mechanical and Thermal Forcing of Tibetan Plateau on the Circulation of the Asian Summer Monsoon Area. Plateau Meteorol 27(1):1-12

Wu TW, Qian ZA (2003) The relation between the Tibetan winter snow and the Asian summer monsoon and rainfall: an observational investigation. J Climate 16:2038-2051

Wu GX, Zhang YS (1998a). Thermal and Mechanical Forcing of the Tibetan Plateau and the Asian Monsoon Onset. Part I: Situating of the Onset. Scientia atmospherica sinica, 22(6):825-838.

Wu GX, Zhang YS (1998b). Tibetan Plateau Forcing and the Timing of the Monsoon Onset over South Asia and the South China Sea. Monthly weather review, 126: 913-927

Wu GX, Zhang YS (1999) Thermal and mechanical forcing of the Tibetan plateau and Asian monsoon onset1 part Il: timing of the onset. Chin J Atmos Sc 23(1):51-61

Wu GX, Mao JY, Duan AM, Zhang Q (2004) Recent progress in the study on the impacts of Tibetan Plateau on Asian Summer climate. Acta Meteorologica Sinica 62(5):528-540

Xiong F, Wang Y (2008) The research on the typical high-impact weather system of thermal depression in southwest China-statistical analysis. J Trop Meteorol 24(4):391-398 (in Chinese)

Xu XD, Tao SY, Wang JZ, Chen LS, Zhou LW, Wang XR (2002) The relationship between water vapor transport features of Tibetan Plateau-monsoon "large Triangle" affecting region and drought-flood abnormality of China. Acta Meteorologica Sinica 60(3):259-265

Xu ZX, Gong TL, Li JY (2008) Decadal trend of climate in the Tibetan Plateauregional temperature and precipitation. Hydrolog Processes 22:3056-3065

Yamamoto R, Sakurai Y (1999) Long-term intensification of extremely heavy rainfall intensity in recent 100 years. World Resour Rev 11(2):271-282

Yan HM, Duan W, Xiao ZN (2003) A study on relation between East Asian winter monsoon and climate change during raining season in China. J Tropical Meteorol 19(4):365-376 (in Chinese)

Yang S, Zhang X, Qi M, NIU Fa-bao (2011) Significant climate characteristic analysis on extremely less rain over Yunnan in autumn, 2009. J Yunnan Univ 33(3):317-324, in Chinese

Yin H, Li Y (2013) Summary of Advance on Drought Study in Southwest China. J Arid Meteorol 31(3):182-193 (in Chinese)

Yue S, Wang CY (2004) The Mann-Kendall Test Modified by Effective Sample Size to Detect Trend in Serially Correlated Hydrological Series. Water Resour Manag 18:201-218 
Zhai PM, Pan XH (2003) Change in extreme temperature and precipitation over northern china during the second half of the 20th century. Acta Meteorologica Sinica 58(supplemental):1-10, in Chinese

Zhai PM, Zhang XB, Wan H, Pan XH (2005) Trends in total precipitation and frequency of daily precipitation extremes over China. J Climate 18:1096-1108

Zhang Q, Liu P, Wu GX (2003) The relationship between the flood and drought over the lower reach of the Yangtze River valley and the SST over the Indian Ocean and the South China Sea. Chin J Atmos Sci 27(6):992-1006

Zhang ZC, Chen X, Wang W, Shi P (2007) Analysis of rainfall trend and extreme events in Guizhou. Earth Environ 35(4):351-356 (in Chinese)

Zhao P, Chen LX (2001) The relationship between the climatic characteristics of heat source in Tibetan plateau and the precipitation over China in the recent 35 years. Sci China (Series D) 31(4):327-332

Zhou L, Wu R (2010) Respective impacts of the East Asian winter monsoon and ENSO on winter rainfall in China. J Geophys Res 115:D02107, doi: 10.1029/2009JD012502

Zhu YX, Ding YH, Xu HG (2007) The decadal relationship between atmospheric heat source of winter and spring snow over Tibetan plateau and rainfall in east China. Acta Meteorologica Sinica 65(6):946-958

\section{Submit your manuscript to a SpringerOpen ${ }^{\circ}$} journal and benefit from:

- Convenient online submission

- Rigorous peer review

- Immediate publication on acceptance

- Open access: articles freely available online

- High visibility within the field

- Retaining the copyright to your article

Submit your next manuscript at $>$ springeropen.com 